\title{
РАЗВИТИЕ РЕГИОНАЛЬНЫХ
}

АЭРОПОРТОВ НА УСЛОВИЯХ ГОСУДАРСТВЕННОЧАСТНОГО ПАРТНЕРСТВА

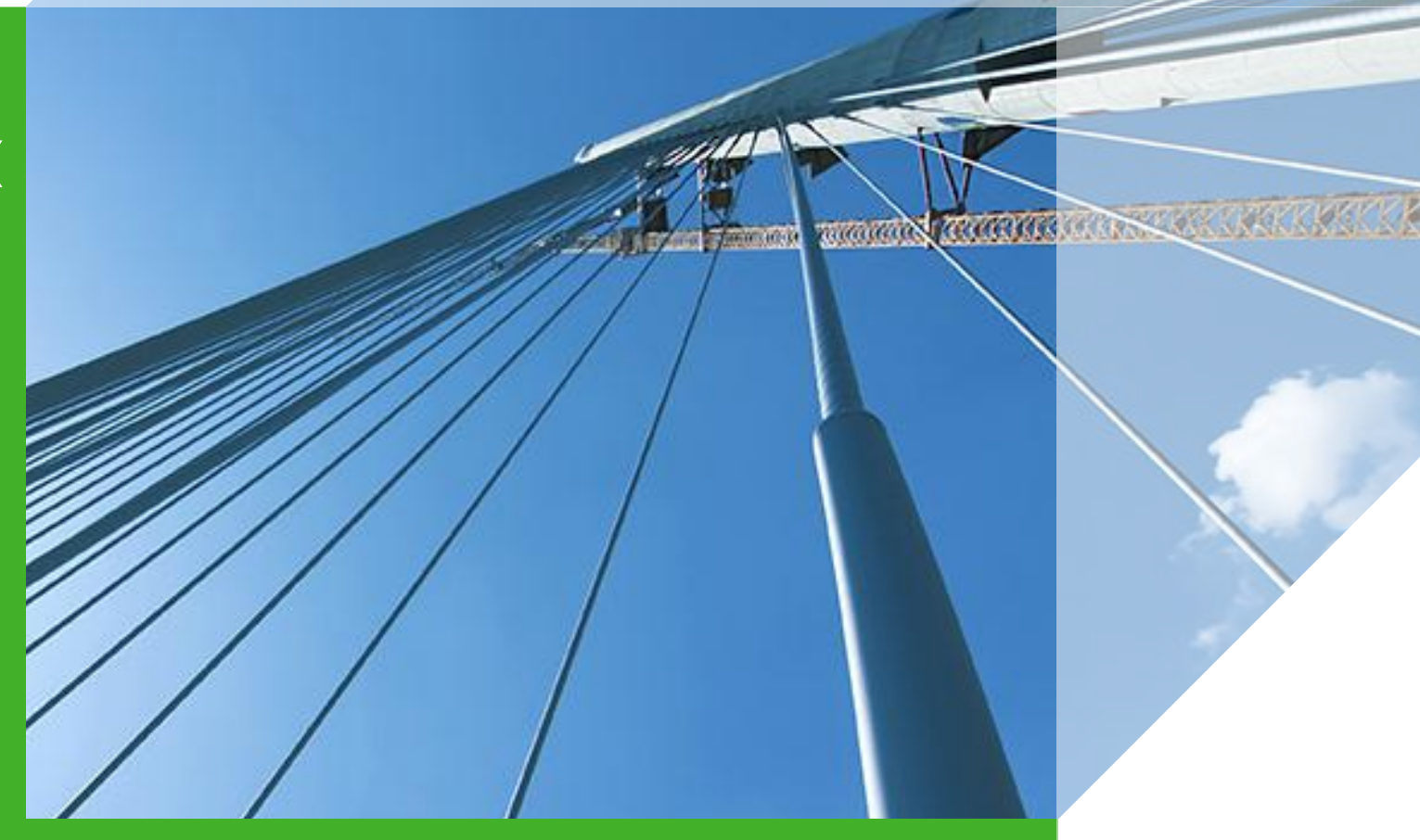

\section{B=5 $\begin{aligned} & \text { Федеральный Центр } \\ & \text { Проектного Финансирования }\end{aligned}$}




\section{Текущая ситуация в отрасли гражданской авиации}

- Начиная с 2000 года в России наблюдается стабильный рост уровня авиаперевозок: в среднем в год пассажирооборот растет на 11,7\%, а грузооборот на $5,4 \%$;

- Износ основных производственных фрондов на воздушном транспорте составляет порядка $50 \%$ **

- В настоящий момент аэродромная сеть сократилась до 1297 аэропортов, что на 40\% меньше чем было 10 лет назад*;

- В соответствии с инновационным вариантом Транспортной стратегии России на период до 2030 года общая потребность отрасли в государственных капитальных вложениях в 2015 - 2020 годах составляет порядка 455,0 млрд. рублей против 247,0 млрд. рублей, предусмотренных в ФЦП «Развитие транспортной системы России». 
Основные цели развития отрасли гражданской авиации, определенные Правительством Российской Федерации*

• Ввод в эксплуатацию после реконструкции 170 взлетно-посадочных полос;

- Повышение транспортной мобильности населения с 1035 до 3325 пасс-км на 1 человека в год;

- Развитие современной и эффрективной транспортной инфраструктуры, обеспечивающей ускорение товародвижения и снижение транспортных издержек в экономике;

- Привлечение внебюджетных источников фринансирования проектов, связанных с развитием аэропортов России.

Одним из ключевых способов достижения перечисленных целей является использование механизмов государственно-частного партнерства.

*Транспортная стратегия России на период до 2030 года и ФЦП «Развитие транспортной системы России» 
Преимущества использования механизмов государственно-частного партнерства при реализации проектов развития региональных аэропортов

- Критические важные объекты аэропортовой инфраструктуры, в частности объекты аэродромного поля, остаются в государственной собственности*;

- Привлечение частных инвестиций позволяет минимизировать объем бюджетных расходов;

- Использование механизмов ГЧП позволяет равномерно распределить риски между публичной и частной стороной;

- Использование механизмов ГЧП позволяет повысить качество управления аэропортами за счет привлечения инвесторов, обладающих соответствующим опытом.

Таким образом, использование механизмов ГЧП позволяет одновременно обеспечить как потребности регионов, так и достижение основных стратегических целей развития отрасли гражданской авиации в России.

*в зависимости от используемой модели ГЧП 


\section{Модели государственно-частного партнерства, применимые при реализации проектов развития аэропортов Российской Федерации}

- Модель ВООТ (Build-Own-Operate-Transfer, Строительство - Собственность - Эксплуатация - Передача):

$\rightarrow$ Создание, реконструкция и эксплуатация на основе ГЧП объектов, входящих в состав имущества аэропорта «Пулково».

- Модель акционерного соглашения:

$\rightarrow$ Cтроительство нового аэровокзального комплекса, реконструкция и модернизация инженерных систем и коммуникаций международного аэропорта «Курумоч», а также его эксплуатация;

$\rightarrow$ Реконструкция и расширение аэровокзального комплекса ОАО «Аэропорт «Кольцово»;

$\rightarrow$ Реконструкция и развития аэропорта «Стригино»;

$\rightarrow$ Cтроительство нового аэровокзального комплекса, реконструкция и модернизация инженерных систем и коммуникаций международного аэропорта «Пермь (Большое Савино)».

- Модель концессионного соглашения:

$\rightarrow$ Развитие аэропортов МАУ;

$\rightarrow$ Cтроительство и эксплуатация аэропорта «Омск-Федоровка». 
Модель ВООТ на примере проекта «Создание, реконструкция и эксплуатация на основе ГЧП объектов, входящих в состав имущества аэропорта «Пулково»

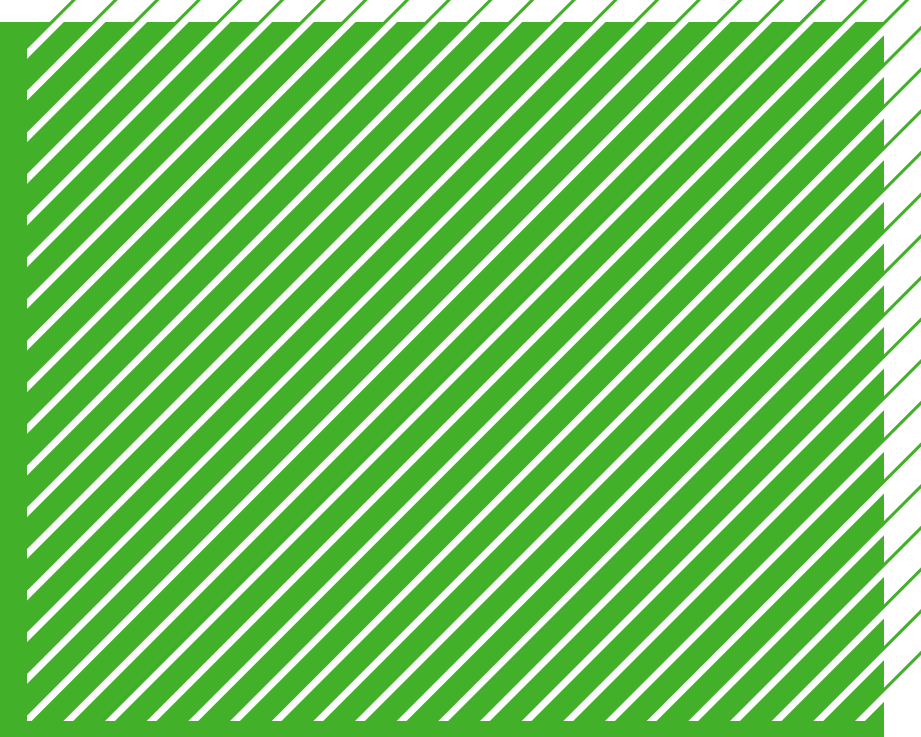

Федеральный Центр
Проектного Финансирования 


\section{Аэропорт «Пулково» \\ Организационно-правовая схема}

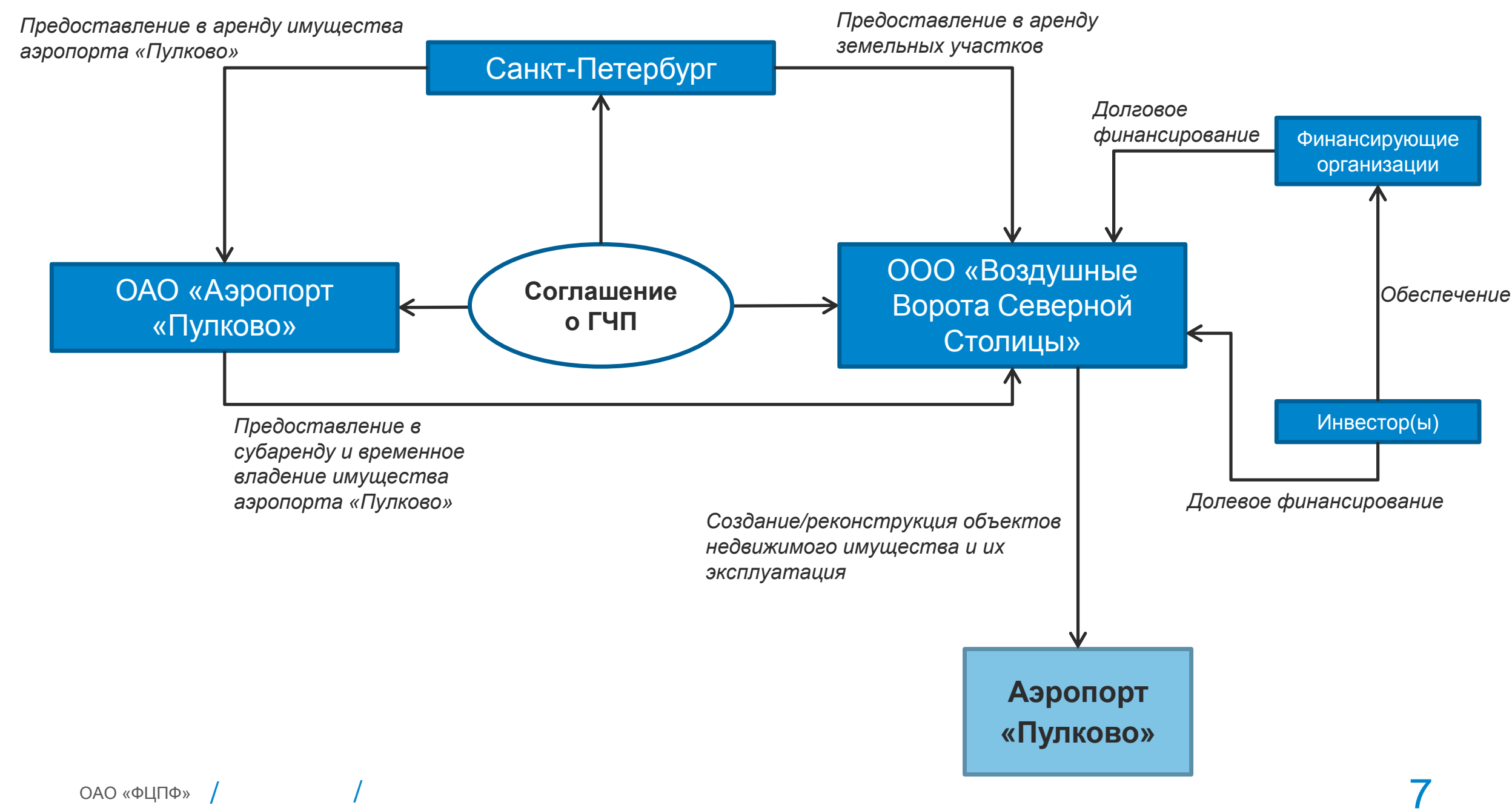




\section{Аэропорт «Пулково» Особенности модели}

- Объекты аэропорта, находящиеся в собственности Санкт-Петербурга и ОАО «Аэропорт «Пулково», передаются в субаренду/аренду инвестору;

- Вновь создаваемые объекты соглашения о ГЧП принадлежат инвестору на праве собственности. По окончании срока действия соглашения о ГЧП право собственности на данные объекты переходят к ОАО «Аэропорт «Пулково»;

- Инвестор осуществляет фринансирование и строительство объектов аэропорта «Пулково» (пассажирского терминала, перронов, гостиницы, бизнес-центра, парковок), а также последующее расширение аэропорта в зависимости от триггерных показателей (объем пассажиропотока и пр.);

- Инвестор осуществляет эксплуатацию аэропорта на период действия соглашения о ГЧП - 30 лет;

- Окупаемость проекта для инвестора обеспечивается за счет доходов от эксплуатации аэропорта;

- По условиям соглашения о ГЧП инвестор ежегодно выплачивает в пользу Санкт-Петербурга роялти в размере $11,5 \%$ от ежегодного оборота*;

- Соглашение о ГЧП не предусматривает государственной поддержки, за исключением содействия инвестору при получении необходимых лицензий, разрешений и согласований.

*ru.cbonds.info/organisations/emitent/14097 
Модель акционерного соглашения на примере проекта «Строительство нового аэровокзального комплекса, реконструкция и модернизация инженерных систем и коммуникаций международного аэропорта «Курумоч», а также его эксплуатация»

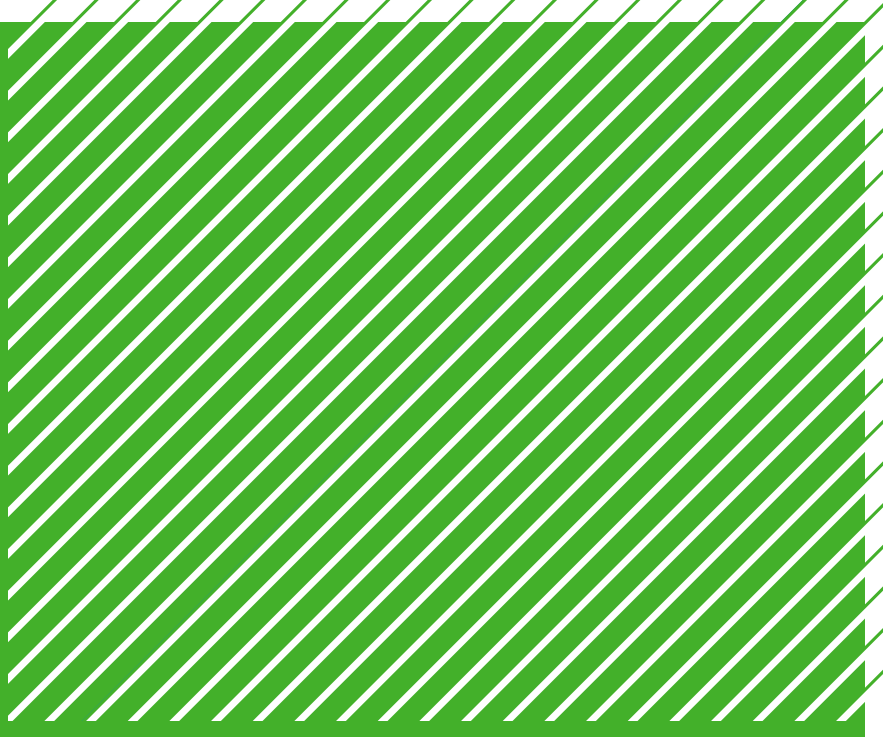
Bes
Федеральный Центр
Проектного Финансирования 


\section{Аэропорт «Курумоч» \\ Организационно-правовая схема}

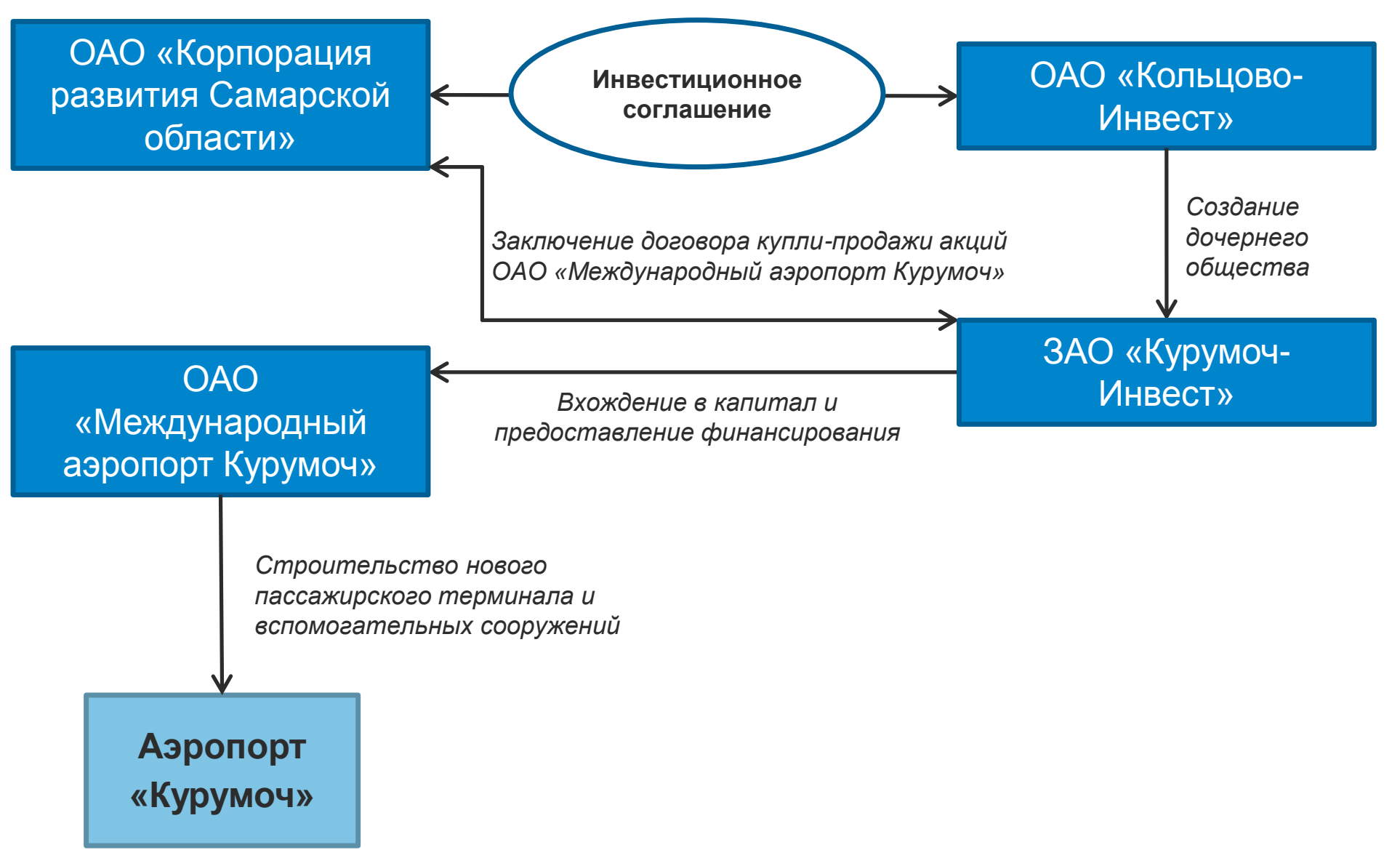




\section{Аэропорт «Курумоч» \\ Особенности модели}

- $\mathrm{B}$

OAO

$$
\text { рамках инвестиционного }
$$

соглашения

инвестор

Самарской

области»

приобретает

$72,6 \%$

акций

ОАО «Международный аэропорт «Курумоч» (далее - ОАО «МАК»), также, после исполнения инвестиционных обязательств инвестор сможет дополнительно приобрести 25,0\% акций общества;

- В случае невыполнения своих обязательств инвестор обязан передать акции ОАО «МАК» обратно в собственность ОАО «Корпорация развития Самарской области»;

- Право собственности на объекты, созданные в рамках инвестиционного соглашения, возникают у ОАО «МАК» и, в свою очередь, разделяются между сторонами инвестиционного соглашения пропорционально их долям в уставном капитале общества;

- Инвестор осуществляет финансирование строительства нового пассажирского терминала, грузового терминала и модернизацию инженерных сетей;

- Эксплуатацию аэропорта осуществляет ОАО «МАК;

- Окупаемость проекта для инвестора обеспечивается за счет доходов от эксплуатации аэропорта;

- В рамках проекта оказывается государственная поддержка - за счет средств федерального бюджета в рамках ФЦП «Развитие транспортной системы России» осуществляется развитие объектов аэродромного поля. 
Модель концессионного

соглашения на примере проекта «Строительство и эксплуатация аэропорта «Омск-Федоровка»

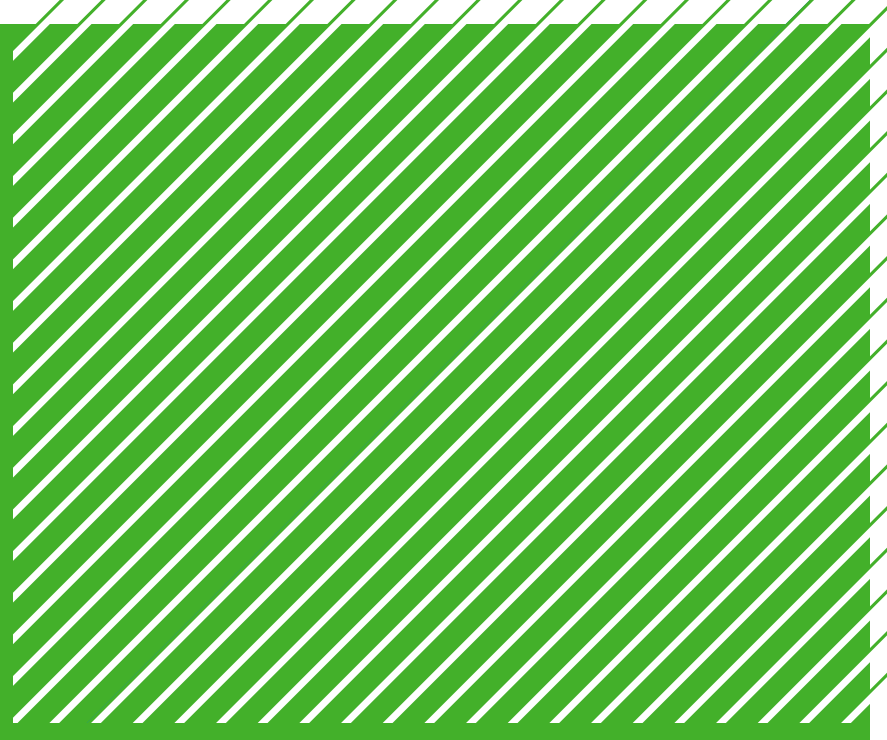

B=5 $\begin{aligned} & \text { Федеральный Центр } \\ & \text { Проектного Финансирования }\end{aligned}$ 


\section{Аэропорт «Омск-Федоровка»}

\section{Организационно-правовая схема}

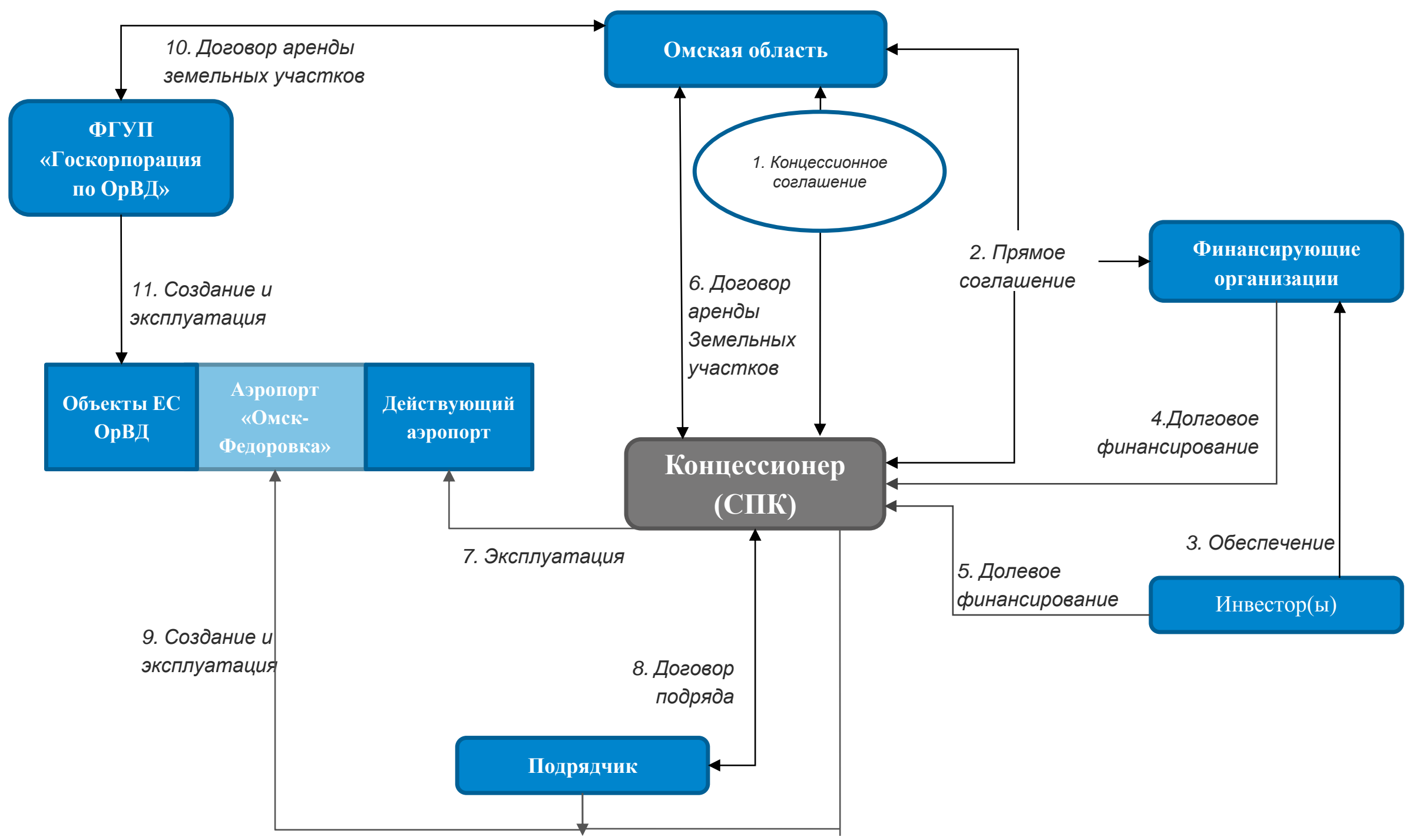




\section{Аэропорт «Омск-Федоровка» \\ Особенности модели}

- В рамках концессионного соглашения предусматривается перенос авиационной деятельности из действующего аэропорта «Омск (Центральный)» в новый аэропорт «Омск-Федоровка»

- Все существующие и создаваемые объекты нового аэропорта в течении всего срока действия соглашения (30 лет) находятся в собственности Омской области;

- Инвестор осуществляет фринансирование и строительство всех объектов аэропорта - объектов аэродромного поля, пассажирского терминала, вспомогательных сооружений и пр. в соответствии с техническими параметрами, определенными концессионным соглашением;

- Окупаемость проекта для инвестора обеспечивается за счет доходов от эксплуатации аэропорта;

- В рамках данной модели предусматривается государственной поддержка инвестора на этапе эксплуатации аэропорта «Омск-Федоровка» за счет предоставления платы концедента, выплачиваемой посредством установления минимального гарантированного дохода концессионера при недостижении которого осуществляются выплаты в форме платы концедента;

- Модель предоставляет Омской области возможность эфффективного контроля над всеми этапами реализации Проекта. 


\section{Федеральный Центр}

BəБ

Проектного Финансирования

\section{СПАСИБО ЗА ВНИМАНИЕ!}

129090, г. Москва, Олимпийский проспект, д. 14, бизнес-центр «Даймонд Холл»

+7 (495) 7773993

$+7(495) 7773992$

project@fcpf.ru

http://www.fcpf.ru 